\title{
Chitinases and chitinase-like proteins as biomarkers in neurologic disorders
}

Rucsanda Pinteac, MSc, Xavier Montalban, MD, PhD, and Manuel Comabella, MD, PhD

Neurol Neuroimmunol Neuroinflamm 2021;8:e921. doi:10.1212/NXI.0000000000000921
Correspondence

Dr. Comabella

manuel.comabella@vhir.org

\section{Abstract}

Chitinases are hydrolytic enzymes widely distributed in nature. Despite their physiologic and pathophysiologic roles are not well understood, chitinases are emerging as biomarkers in a broad range of neurologic disorders, where in many cases, protein levels measured in the CSF have been shown to correlate with disease activity and progression. In this review, we will summarize the structural features of human chitinases and chitinase-like proteins and their potential physiologic and pathologic functions in the CNS. We will also review existing evidence for the role of chitinases and chitinase-like proteins as diagnostic and prognostic biomarkers in inflammatory, neurodegenerative diseases, and psychiatric disorders. Finally, we will comment on future perspectives of chitinase studies in neurologic conditions. 


\section{Glossary}

$\mathbf{A} \boldsymbol{\beta}=\beta$-amyloid; $\mathbf{A M C a s e}=$ acidic mammalian chitinase; CHI3L1 = chitinase-3-like 1; CHI3L2 = chitinase-3-like 2; CHIT1 = chitotriosidase; CIS = clinically isolated syndrome; CJD = Creutzfeldt-Jakob disease; CLP = chitinase-like protein; CRTH2 = prostaglandin D2 receptor 2; EAE = experimental autoimmune encephalomyelitis; Erk = extracellular signal-regulated kinase; FAK = focal adhesion kinase; FTD = frontotemporal dementia; GH18 = 18 glycosyl hydrolase; IL-13R $\mathbf{2}=$ interleukin-13 receptor 2 2; IFN = interferon; $\mathbf{M A P K}=$ mitogen-activated protein kinase; $\mathbf{M C I}=$ mild cognitive impairment; $\mathbf{N F}-\mathbf{k B}=$ nuclear factor kappa B; OVGP1 = oviductin-specific glycoprotein; PCS = post-concussion syndrome; $\mathbf{P D}=$ Parkinson disease; $\mathbf{P P M S}=$ primary progressive MS; RRMS = relapsing-remitting MS; SI-CLP = stabilin-1-interacting CLP; SPMS = secondary progressive MS; TGF- $\beta=$ transforming growth factor $\beta$; Th2 $=$ T-helper cell type 2 ; TIM = triosephosphate isomerase; TMEM219 = transmembrane protein 219; TNF $\alpha=$ tumor necrosis factor alpha.

Biomarkers are important in neurologic disorders to aid in the distinction between diseases with similar clinical phenotypes or shared pathophysiologic mechanisms, to monitor and stratify patients according to disease activity and progression, and to predict the response to therapies. Biomarkers can also be useful for a better understanding of disease etiopathogenesis and, in some instances, may become therapeutic targets for particular diseases. In neurologic conditions, they can be roughly divided into biomarkers of inflammation and neurodegeneration. It is well known that neuroinflammation is not only an important component of more classical inflammatory disorders like MS but it is also an essential mechanism in the pathophysiology of more purely neurodegenerative disorders such as Alzheimer disease or amyotrophic lateral sclerosis, among others. Despite their precise function is still unknown, chitinases are emerging as biomarkers in inflammatory and neurodegenerative disorders where levels measured in body fluids may tag the neuroinflammatory component and overall reflect the degree of astrocyte or microglial participation in the pathophysiology of the different neurologic conditions. This review will summarize existing evidence about the role of chitinases as biomarkers in a number of inflammatory and neurodegenerative diseases and their potential implication in the CNS physiopathology. References for the review were identified by searches of the PubMed database literature from 1974 until September 2020 using the search terms "chitinase" or "chitotriosidase" together with the neurologic diseases of the CNS and psychiatric disorders included in the review: "multiple sclerosis," "Alzheimer's disease," "amyotrophic lateral sclerosis," "stroke," "traumatic brain injury," "Creutzfeldt-Jakob disease," "Parkinson's disease," "HIV encephalitis," "schizophrenia," or "bipolar disorder." Only articles published in English were reviewed. The final reference list was obtained mainly based on originality and relevance to the topic of the review.

\section{Human chitinases: genes, family, structure, and function}

Chitin is the second most abundant polysaccharide in nature and an essential structural component in numerous organisms including arthropods, protozoan parasites, nematodes, bacteria, and fungi. ${ }^{1}$ Chitin synthetases and chitinases are responsible for chitin metabolism in chitin-containing organisms. ${ }^{1}$ Despite the absence of endogenous chitin or chitin synthases genes, mammals express true chitinases with enzymatic activity and homologous structurally related chitinase-like proteins (CLPs) that lack enzymatic activity but still can bind to chitin with high affinity. ${ }^{2}$

Because of their amino acid sequence similarities, human chitinases are classified into the 18 glycosyl hydrolase (GH18) family. $^{2-4}$ The human protein family encodes 2 true chitinases, chitotriosidase (CHIT1), and acidic mammalian chitinase (AMCase), and several CLPs: chitinase-3-like 1 (CHI3L1), chitinase-3-like 2 (CHI3L2), oviductin-specific glycoprotein (OVGP1), and stabilin-1-interacting CLP (SICLP). ${ }^{5}$ Proteins of the GH18 family are composed of the following structural components: a signal peptide, no/several serine-threonine-rich linkers, GH18 catalytic domains, and no/several cysteine-rich carbohydrate or chitin-binding domains. ${ }^{4}$ The triosephosphate isomerase (TIM) barrel domain is the catalytical domain of the GH18 superfamily. ${ }^{6}$ Enzymatically active chitinases have a glutamate residue that acts as a proton donor in their catalytic center and an aspartic acid that stabilizes the substrate. ${ }^{7}$ Because of the substitution of critical amino acids in the catalytic center, CLPs have lost their chitinolytic activity but still conserve the TIM barrel and the chitin-binding domain. ${ }^{8}$ Molecular phylogenetic studies suggest that a first duplication event allowed the specialization of CHIT1 and AMCase. The subsequent evolution of CLPs is a product of posterior gene duplications and loss of function mutations. ${ }^{3,8}$ Except for the SI-CLP gene that is located on chromosome 11, all human GH18 members are located on chromosome $1 .^{8}$

Table 1 summarizes main properties and function of chitinases and CLPs. CHIT1 and AMCase are true chitinases that can degrade chitin. The main physiologic role of human true chitinases is the defense and clearance of chitin and chitinous organisms. ${ }^{9}$ CHIT 1 was the first human chitinase discovered and characterized in macrophages from patients with Gaucher disease. ${ }^{10,11}$ CHIT1 is expressed in activated macrophages on diverse triggering stimuli, ${ }^{12-14}$ neutrophils granules, ${ }^{15}$ and 
Table 1 Human chitinases and CLPS

\begin{tabular}{|c|c|c|c|c|c|c|}
\hline Name & $\begin{array}{l}\text { Gene } \\
\text { symbol }\end{array}$ & $\begin{array}{l}\text { Catalytic } \\
\text { activity }\end{array}$ & Glycoprotein & Cellular source & $\begin{array}{l}\text { Subcellular } \\
\text { location }\end{array}$ & Function \\
\hline Chitotriosidase & CHIT1 & + & + & $\begin{array}{l}\text { Macrophages, } \\
\text { neutrophils, and } \\
\text { microglia }\end{array}$ & $\begin{array}{l}\text { Extracellular } \\
\text { region or } \\
\text { secreted; } \\
\text { lysosome }\end{array}$ & $\begin{array}{l}\text { Degrades chitin, chitotriose, and } \\
\text { chitobiose; may participate in the defense } \\
\text { against nematodes and other chitinous } \\
\text { pathogens; and plays a role in reactive } \\
\text { gliosis }\end{array}$ \\
\hline $\begin{array}{l}\text { Acidic mammalian } \\
\text { chitinase }\end{array}$ & CHIA & + & + & Macrophages & $\begin{array}{l}\text { Extracellular } \\
\text { region or } \\
\text { secreted }\end{array}$ & $\begin{array}{l}\text { Degrades chitin and chitotriose; may } \\
\text { participate in the defense against } \\
\text { nematodes, fungi, and other pathogens; } \\
\text { and plays a role in T-helper cell type } 2 \\
\text { (Th2) immune response }\end{array}$ \\
\hline
\end{tabular}

Chitinase-3-like CHI3L1 - $\quad+\quad+\quad$ Monocytes/ Extracellular May play a role in tissue remodeling and

protein $1 / Y K L-40$

macrophages,

region or

in the capacity of cells to respond to and

chondrocytes,

secreted cope with changes in their environment; positive regulation of angiogenesis; plays a role in Th2 inflammatory response and interleukin (IL)-13-induced inflammation, regulating allergen sensitization, inflammatory cell apoptosis, dendritic cell accumulation, and M2 macrophage differentiation; facilitates invasion of pathogenic enteric bacteria into colonic mucosa and lymphoid organs; mediates activation of AKT1 signaling pathway and IL8 production in colonic epithelial cells; regulates antibacterial responses in the lung by contributing to macrophage bacterial killing, controlling bacterial dissemination, and augmenting host tolerance; regulates hyperoxia-induced injury, inflammation, and epithelial apoptosis in the lung; and plays a role in reactive gliosis

\begin{tabular}{|c|c|c|c|c|c|c|}
\hline $\begin{array}{l}\text { Chitinase-3-like } \\
\text { protein 2/YKL-39 }\end{array}$ & $C H I 3 L 2$ & - & - & $\begin{array}{l}\text { Cartilage } \\
\text { chondrocytes }\end{array}$ & $\begin{array}{l}\text { Extracellular } \\
\text { region or } \\
\text { secreted }\end{array}$ & $\begin{array}{l}\text { Growth/differentiation factor for articular } \\
\text { chondrocytes and may play a role in } \\
\text { immune response and tissue remodeling }\end{array}$ \\
\hline $\begin{array}{l}\text { Oviductal } \\
\text { glycoprotein } 1\end{array}$ & OVGP1 & - & + & $\begin{array}{l}\text { Oviductal epithelial } \\
\text { cells }\end{array}$ & $\begin{array}{l}\text { Extracellular } \\
\text { region or } \\
\text { secreted }\end{array}$ & $\begin{array}{l}\text { Binds to oocyte zona pellucida in vivo and } \\
\text { may play a role in the fertilization process } \\
\text { and/or early embryonic development }\end{array}$ \\
\hline $\begin{array}{l}\text { Stabilin-interacting } \\
\text { chitinase-like } \\
\text { protein, chitinase } \\
\text { domain-containing } \\
\text { protein } 1\end{array}$ & CHID1 & - & + & Macrophages & $\begin{array}{l}\text { Extracellular } \\
\text { region or } \\
\text { secreted; } \\
\text { lysosome }\end{array}$ & $\begin{array}{l}\text { Binds to stabilin- } 1 \text {; saccharide- and LPS- } \\
\text { binding protein with possible roles in } \\
\text { pathogen sensing and endotoxin } \\
\text { neutralization }\end{array}$ \\
\hline
\end{tabular}

cells that exhibit phagocytic activity such as monocyte-derived cells, Kupffer cells, osteoclasts, and dendritic cells. ${ }^{16}$ Elevated plasma levels of CHIT1 are found in disorders that involve macrophage activation such as atherosclerosis, ${ }^{17}$ sarcoidosis, $^{18} \mathrm{MS},{ }^{19}$ and infectious diseases like malaria ${ }^{20}$ or fungal infections. Existing data suggest that CHIT1 plays a role in inflammation not only as a defense against chitinous pathogens but also as a mediator of the innate immune response (table 1).

AMCase was the second chitinase to be discovered and is mainly expressed in the stomach and to a lesser extent in the lung, ${ }^{21}$ which are exposed to exogenous chitin through food ingestion and air inhalation, respectively. AMCase is stable at extremely acid $\mathrm{pH}$ and may be involved in processing the exogenous chitin that enters the digestive tract. ${ }^{22}$ In the lung, AMCase is expressed and secreted into the airway lumen by the secretory epithelial cells and type 2 alveolar cells. ${ }^{23} \mathrm{Be}-$ sides, AMCase has been pointed out as a critical regulator of pulmonary T-helper cell type 2 (Th2) inflammation in murine models. $^{24,25}$

CLPs can bind to chitin but not to degrade it. CLPs exhibit lectin properties and can bind to extracellular matrix components such as hyaluronan or proteoglycans and cell surface glycosaminoglycans. ${ }^{26}$ The physiologic functions of CLPs are not entirely understood, but they appear to be involved in a plethora of biological processes, including tissue remodeling, inflammation, and regulation of the immune response.

CHI3L1 or YKL-40 is by far the most described CLP because of its implication in diverse pathologic conditions. CHI3L1 is a $40-\mathrm{kD}$ glycoprotein that was first discovered as an abundant molecule in media from cultured chondrocytes and synovial 
Table 2 Summary of CHI3L1 studies in neurologic disorders

\begin{tabular}{|c|c|c|c|}
\hline Disease & Comments: findings & Correlations $^{a}$ & CNS expression \\
\hline \multirow[t]{5}{*}{ MS } & $\begin{array}{l}\text { High levels in early phases are associated with } \uparrow \text { risk for MS and } \\
\text { neurologic disability }(\mathrm{CSF})^{\mathrm{e} 15, \mathrm{e} 23-\mathrm{e} 25}\end{array}$ & $\begin{array}{l}\text { NFL/CXCL13/ } \\
\text { MMP-9 }\end{array}$ & $\begin{array}{l}\text { Astrocytes and macrophage/microglial cells } \\
\text { from chronic active lesions with high and low } \\
\text { inflammatory activity }\end{array}$ \\
\hline & Levels correlate with clinical and radiologic disease activity (CSF) ${ }^{\mathrm{e} 26}$ & & \\
\hline & $\begin{array}{l}\text { Levels are increased in progressive forms of the disease (CSF and } \\
\text { blood) })^{\mathrm{e} 15, \mathrm{e} 27, \mathrm{e} 28}\end{array}$ & & \\
\hline & Predictor of progression to an SPMS phase of the disease (CSF) ${ }^{\mathrm{e} 28}$ & & \\
\hline & $\begin{array}{l}\text { Associated with brain volume loss (CSF) }{ }^{\mathrm{e} 23, \mathrm{e} 29} \text { and the therapeutic } \\
\text { response to IFN } \beta \text { (blood) }\end{array}$ & & \\
\hline \multirow[t]{6}{*}{$\begin{array}{l}\text { Alzheimer } \\
\text { disease (AD) }\end{array}$} & $\begin{array}{l}\text { Levels are } \uparrow \text { in preclinical, prodromal, and demential cases of AD } \\
\text { vs CNC (CSF) }\end{array}$ & $\begin{array}{l}\text { Tau (total and } \\
\text { phospho-tau)/ } \\
\text { ß-amyloid }\end{array}$ & In a subset of astrocytes from the frontal cortex \\
\hline & $\begin{array}{l}\text { High levels are associated with } \uparrow \text { risk of } A D \text { in CNCs or patients } \\
\text { with } \mathrm{MCl}(\mathrm{CSF})^{\mathrm{e} 37, \mathrm{e} 39, \mathrm{e} 42}\end{array}$ & & \\
\hline & Levels increase over time in patients with $\mathrm{AD}$ and $\mathrm{MCI}(\mathrm{CSF})^{\mathrm{e} 42}$ & & \\
\hline & $\begin{array}{l}\text { High levels are associated with cortical thinning in parietal and } \\
\text { temporal areas (CSF) }\end{array}$ & & \\
\hline & $\begin{array}{l}\text { Controversial results as diagnostic biomarker to distinguish AD } \\
\text { from FTD (CSF) }{ }^{\mathrm{e} 37, \mathrm{e} 38, \mathrm{e} 40, \mathrm{e} 41, \mathrm{e} 44}\end{array}$ & & \\
\hline & Levels $\uparrow$ in AD vs a-synucleinopathies $(C S F)^{e 38, e 45}$ & & \\
\hline \multirow{4}{*}{$\begin{array}{l}\text { Amyotrophic } \\
\text { lateral } \\
\text { sclerosis (ALS) }\end{array}$} & $\begin{array}{l}\text { Levels are } \uparrow \text { in ALS vS ALS mimics, healthy controls, and other } \\
\text { disease controls (CSF) }\end{array}$ & NFL/pNFH & Astrocytes from the spinal and frontal cortex \\
\hline & Controversial results as prognostic biomarker ${ }^{\mathrm{e} 18, \mathrm{e} 53, \mathrm{e} 55, \mathrm{e} 57, \mathrm{e} 59, \mathrm{e} 60}$ & & \\
\hline & $\begin{array}{l}\text { Levels are longitudinally stable or slightly increase over } \\
\text { time } \mathrm{e}^{\mathrm{e} 18, \mathrm{e} 53, \mathrm{e} 56, \mathrm{e} 57}\end{array}$ & & \\
\hline & Associated with cognitive impairment (CSF) ${ }^{\mathrm{e} 18}$ & & \\
\hline Stroke & $\begin{array}{l}\text { Levels correlate with infarct volume, stroke severity, and } \\
\text { functional outcome (blood) }\end{array}$ & & $\begin{array}{l}\text { Transient expression in astrocytes proximal to } \\
\text { the injury in the acute stage }\end{array}$ \\
\hline
\end{tabular}

Independent predictor of the clinical outcome of the LAA stroke (blood) ${ }^{\mathrm{e} 67}$

High baseline levels are associated with an increased risk of stroke (blood) ${ }^{\text {e68-e71 }}$

Traumatic brain injury

(TBI)
Levels increase at day 1 postinjury, peak at day 4, and decrease by day $6(\mathrm{CSF})^{\mathrm{e} 75}$
IL-1 $\beta$, TNFa, and

CRP
Transient expression in astrocytes in the contusional and pericontusional area ${ }^{b}$

May be predictor of worse survival outcome (CSF)

Levels correlate with volume of intracranial lesion (blood) ${ }^{\mathrm{e} 6}$

Associated with level of consciousness after TBI (blood) ${ }^{\mathrm{e} 76}$

Levels are $\uparrow$ in patients with PCS vs healthy controls and correlate with symptom severity and lifetime number of contusions (CSF)
e77

\begin{tabular}{lll}
\hline $\begin{array}{l}\text { Creutzfeld- } \\
\text { Jakob disease } \\
\text { (CJD) }\end{array}$ & $\begin{array}{l}\text { Levels are } \uparrow \text { in patients with CJD vs patients with Alzheimer } \\
\text { disease, FTD, and also controls (CSF) }\end{array}$ & \begin{tabular}{l} 
Tau protein \\
\cline { 2 - 3 }
\end{tabular} \\
\cline { 2 - 3 } & $\begin{array}{l}\text { Levels are } \uparrow \text { in patients with CJD vs patients with } \\
\text { neurodegenerative dementias, neurologic controls, and healthy } \\
\text { controls (blood) }\end{array}$ & $\begin{array}{l}\text { Reactive protoplasmic and perivascular } \\
\text { astrocytes and fibrillar astrocytes in the WM }\end{array}$ \\
\hline $\begin{array}{l}\text { Parkinson } \\
\text { disease (PD) }\end{array}$ & $\begin{array}{l}\text { Levels are } \uparrow \text { in patients with PD after 2 y of follow-up compared } \\
\text { with baseline (CSF) }\end{array}$ \\
\cline { 2 - 3 } & Levels correlate with cognitive impairment (CSF) \\
\hline
\end{tabular}


Table 2 Summary of CHI3L1 studies in neurologic disorders (continued)

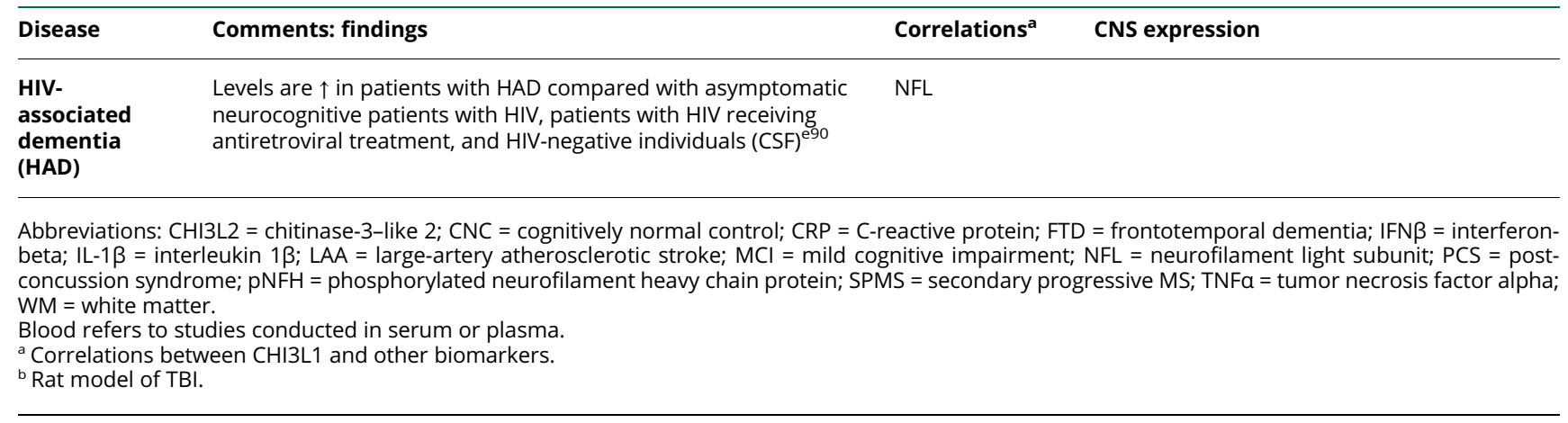

cells. ${ }^{27}$ Despite CHI3L1 is expressed in a wide variety of cells, including macrophages, ${ }^{28}$ osteoclasts, ${ }^{29}$ microglia, and astrocytes, ${ }^{30}$ its ligands and signaling have only recently started to be unraveled. CHI3L1 signaling is complex and depends on the cellular context (summarized in figure 1). Recently, hyaluronan was described as the physiologic ligand of CHI3L1. ${ }^{26}$ Several studies showed physical interaction of CHI3L1 with the interleukin-13 receptor $\alpha 2$ (IL-13R $\alpha 2)$ and transmembrane protein 219 (TMEM219). ${ }^{31-33}$ The multimeric complex formed by CHI3L1, IL-13Ra2, and TMEM219 was found to activate mitogen-activated protein kinase (MAPK), protein kinase $\mathrm{B} / \mathrm{AKT}$ and $\mathrm{Wnt} / \beta$-catenin signaling, and mediate a wide range of CHI3L1 effector responses including, among others, regulation of lung oxidant injury response and apoptosis, macrophage pyroptosis and inflammasome activation, transforming growth factor $\beta 1$ (TGF- $\beta 1$ ) induction, and melanoma metastasis. ${ }^{31,32}$ In addition, M2 macrophage-secreted CHI3L1 promoted gastric and breast cancer metastasis via IL-13R $\alpha 2$ by activating the MAPK signaling pathway and leading to an upregulation of matrix metalloproteinase genes, thus facilitating extracellular matrix degradation. ${ }^{33} \mathrm{CHI} 3 \mathrm{~L} 1$ has also been reported to interact with the prostaglandin D2 receptor $2(\mathrm{CRTH} 2)^{34}$ and with galectin- $3^{35}$ leading to an exaggerated fibroproliferative response and dysregulation of apoptosis in Hermansky-Pudlak syndrome. Moreover, CHI3L1 has been reported to bind to the side chain molecules of syndecan- 1 and integrin $\alpha v \beta 5$ activating downstream focal adhesion kinase (FAK) and MAPK and inducing tumor angiogenesis. ${ }^{36} \mathrm{CHI} 3 \mathrm{~L} 1$ interaction with $\mathrm{CD} 44 \mathrm{v} 3$ has been shown to induce epithelial-to-mesenchymal transition through $\beta$-catenin/extracellular signal-regulated kinase (Erk)/Akt signaling in gastric cancer. ${ }^{37} \mathrm{CHI} 3 \mathrm{~L} 1$ was also described as a RAGE receptor (receptor for advanced glycation end products) binding partner activating STAT3, $\beta$-catenin, and nuclear factor kappa B (NF- $\mathrm{kB}$ ) pathways and stimulating the proliferation of intestinal epithelial cells. ${ }^{38}$ In summary, the binding of CHI3L1 to its receptors activates multiple and heterogeneous signaling pathways including ERK1/2, PI3K, Wnt/ $\beta$-catenin, FAK861/397, or MAPK leading to different cellular outcomes. ${ }^{39}$
CHI3L1 is an acute-phase reactant, secreted by immune cells in response to proinflammatory stimuli such as IL6 and interferon (IFN) $-\gamma$, IL-1 $\beta$, or tumor necrosis factor alpha $(\mathrm{TNF} \alpha) .{ }^{40} \mathrm{CHI} 3 \mathrm{~L} 1$ is expressed during the differentiation and maturation of dendritic cells in a time-dependent manner. ${ }^{29}$ Surprisingly, increased expression of CHI3L1 has been observed in both M1- and M2-polarized macrophages, ${ }^{33}$ suggesting pleiotropic functions during inflammation. CHI3L1 seems to have a role regulating the Th1/Th2 inflammatory balance. ${ }^{41}$ Upregulation of CHI3L1 is a shared biomarker of numerous inflammatory nonneurologic conditions such as inflammatory bowel disease, cardiovascular disease, rheumatoid arthritis, diabetes, chronic obstructive pulmonary disease, atherosclerosis, and cancer. ${ }^{42-45}$ CHI3L1 expression has been demonstrated in many types of neoplastic cells and is associated with tumor progression $^{46}$ and epithelial-mesenchymal transition. ${ }^{37}$ Moreover, CHI3L1 is a potent angiogenic factor that promotes tumor angiogenesis. ${ }^{47}$ Despite the apparent pathophysiologic implication of CHI3L1 in both inflammatory and reparative responses, there are many unknowns. CHI3L1 has the potential to be a therapeutic target in conditions characterized by chronic inflammation, fibrosis, and tissue remodeling.

CHI3L2 or YKL-39 is closely related to CHI3L1 in size and sequence, although has several structural differences. ${ }^{48}$ In contrast to CHI3L1, CHI3L2 is not a glycoprotein. $\mathrm{CHI} 3 \mathrm{~L} 2$ was discovered as a $39-\mathrm{kD}$ protein from the conditioned medium of human articular cartilage chondrocyte primary cultures. CHI3L1 and CHI3L2 have been shown to activate ERK1/2 in 293 and U373 cells leading to different outcomes: CHI3L1 activates cell proliferation, whereas CHI3L2 decreases it. ${ }^{49} \mathrm{CHI} 3 \mathrm{~L} 2$ is a recognized biomarker of the osteoarthritic condition and is thought to be a novel growth/differentiation factor for articular cartilage chondrocytes. ${ }^{50}$ However, how CHI3L2 regulates cell proliferation and differentiation is not yet understood due to a lack of knowledge about its receptors and intracellular signaling pathways. CHI3L2 is strongly expressed in tumor-associated macrophages. ${ }^{51}$ In vitro studies showed that TGF- $\beta$ and IL- 4 induce the expression of CHI3L2 in 
M2-polarized macrophages and that $\mathrm{CHI} 3 \mathrm{~L} 2$ acts as a proangiogenic and monocyte recruiting factor. ${ }^{52}$ Similar to CHI3L1, CHI3L2 function is also associated with immune response and tissue remodeling.

Finally, OVGP1 and SI-CLP are the less described CLPs. OVGP1 is a $120-\mathrm{kD}$ glycoprotein, which is specifically secreted into the oviductal lumen and may be implicated in the fertilization process. ${ }^{53}$ SI-CLP, the most recent identified CLP, was first discovered as a novel interacting partner of stabilin-1, and it appears to be involved in macrophage alternative activation. ${ }^{54}$

\section{Role of chitinases and CLPs in the CNS}

For many years, the CNS was thought to be an immunoprivileged site. Nowadays, it is accepted that the immune response takes place in the brain involving peripheral and local components. Neuroinflammation plays a role not only in primarily inflammatory diseases such as MS but also in nonimmunologic disorders like Alzheimer disease, amyotrophic lateral sclerosis, acute CNS injury, and psychiatric disorders. ${ }^{55}$ Neuroinflammation is a physiologic process triggered by a wide range of harmful stimuli and involves a complex interplay of distinct cell types, including microglia, astrocytes, other glial cells, and peripheral components. It is necessary for tissue repair, recovery, and regeneration. Nevertheless, it can be a double-edged sword exerting detrimental effects when dysregulated or chronic. In this regard, chitinases and CLPs have been extensively described as markers of neuroinflammation and reactive gliosis in a wide variety of neurologic disorders. For some of these disorders, chitinases and CLPs have also been proposed as prognostic biomarkers and potential therapeutic targets. Notwithstanding, their specific role in neuroinflammation remains to be elucidated, and it appears to be disease or context specific.

Despite CHIT1 implication in diverse neurologic diseases, few studies addressing its function and signaling in the CNS are available. CHIT1 expression in the CNS was mainly attributed to microglia and infiltrating peripheral macrophages. ${ }^{56}$ CHIT1 immunoreactivity seems to be limited to microglial cells in mixed mouse primary glial cultures. ${ }^{57}$ Moreover, exposure of the cultured microglial cells to CHIT 1 caused morphologic transformations indicative of an activated status. ${ }^{57}$ However, M1/M2 polarization was not investigated in their study. Oligomeric $\beta$-amyloid $(A \beta)$ pretreatment induced CHIT1 expression in a cultured N9 microglial cell line. ${ }^{58} \mathrm{~A}$ significant reduction in $\mathrm{A} \beta$ oligomers was reported in the D-galactose and aluminum chloride-induced Alzheimer disease animal models after treatment with CHIT1, suggesting that the $A \beta$ oligomer deposition is influenced by CHIT 1 activity. ${ }^{58}$ In addition, the proinflammatory cytokines TNF $\alpha$ and IL- $1 \beta$ were significantly decreased in the brain of CHIT 1 treated animals and N9 microglial cells, whereas the M2 alternative activation markers arginase 1 and mannose receptor type C $1 /$ CD206 were significantly increased. ${ }^{58}$ The findings provided by this study suggest that CHIT1 may exert a protective role through the regulation of microglial polarization. In addition, CHIT 1 was reported to increase TGF- $\beta 1$-induced $A \beta$ phagocytosis by acting as a cofactor of TGF- $\beta 1$ in the N9 microglial cell line. ${ }^{59}$ Of interest, CHIT 1 did not affect $A \beta$ uptake by itself, but enhanced the TGF- $\beta 1$-induced expression of TGF- $\beta$ receptor 1 and activation of Smad signaling. ${ }^{59}$ Despite these studies, additional research addressing CHIT1 expression, role, and signaling in the CNS is still required.

CHI3L1 source in the human CNS has been mostly associated with reactive astrocytes in distinct neuroinflammatory contexts. ${ }^{60, \mathrm{e} 1, \mathrm{e} 2}$ Besides, CHI3L1 expression was reported both during in vitro human astrocytes differentiation from neural progenitors and during postnatal brain development in mouse, coincident with astrocyte differentiation. ${ }^{\mathrm{e}}$

There are several in vitro studies that explore CHI3L1 effects and signaling on different cellular types of the CNS (figure 2). Treatment with the proinflammatory cytokines IL-1 $\beta$ and TNF $\alpha$ induced CHI3L1 expression in primary human astrocytes $^{\mathrm{e} 2}$ and in hiPSC-derived astrocytes. ${ }^{\mathrm{e} 4}$ The IL-1 $\beta$ and $\mathrm{TNF} \alpha$-induced $\mathrm{CHI} 3 \mathrm{~L} 1$ transcription was completely inhibited by IL-1R and TNF $\alpha$ R antagonists and partially by NF-kB inhibitors. ${ }^{\mathrm{e} 2} \mathrm{CHI} 3 \mathrm{~L} 1$ has been described as a migration factor for primary human astrocytes, ${ }^{\mathrm{e} 2 \mathrm{e} 3}$ and human astrocytes stably transfected with CHI3L1 exhibited radiation resistance and increased invasion in vitro of glioma cells. ${ }^{\mathrm{e} 5}$ Moreover, CHI3L1 expression is induced in glioblastoma tumor-associated astrocytes promoting proliferation and migration through IL-13R 22 signaling. ${ }^{\text {e6 }}$

Several groups reported CHI3L1 effects on oligodendrogenesis. For instance, in a cellular model of Alexander disease, a leukodystrophy caused by mutations in the GFAP gene, increased astrocyte-secreted CHI3L1 mediated the inhibition of oligodendrocyte progenitor cell proliferation and myelination through CRTH2 signaling. ${ }^{\mathrm{e} 7}$ On the other hand, Starossom et al. described that CHI3L1 promoted in vitro oligodendrogenesis in human neural stem cells. ${ }^{\text {8 }}$

Regarding CHI3L1 effects on neurons, 2 independent groups reported a dose-dependent neurotoxic effect on mouse primary neuronal cultures. ${ }^{30, e 9}$ The mechanisms driving the CHI3L1-induced neuronal dysfunction and death are still unknown.

CHI3L1 knockout mice exhibited worse outcomes and exacerbated gliosis both in stroke $\mathrm{e}^{\mathrm{e} 10}$ and traumatic brain injury ${ }^{\text {el1 }}$ models suggesting a protective role of CHI3L1 in acute neuroinflammation. In the stroke model of middle cerebral arterial occlusion, $\mathrm{CHI} 3 \mathrm{~L} 1 \mathrm{KO}$ mice display accelerated stroke development through enhancement of neuroinflammation because of decreased STAT6-dependent 
Table 3 Summary of CHIT1 and CHI3L2 studies in neurologic disorders

\begin{tabular}{|c|c|}
\hline Disease & Comments: findings \\
\hline \multirow[t]{5}{*}{ MS } & CHI3L2 \\
\hline & $\begin{array}{l}\text { High CSF levels in early phases were associated with } \uparrow \text { risk for MS in } 1 \text { study, }{ }^{\mathrm{e} 16} \text { but another study in CSF and serum failed } \\
\text { to find such association }{ }^{\mathrm{e} 15}\end{array}$ \\
\hline & Levels are $\uparrow$ in patients with RRMS vs SPMS ${ }^{\mathrm{e} 15}$ \\
\hline & CHIT1 \\
\hline & Correlation of CSF levels with long-term disease activity ${ }^{\mathrm{e} 4}$ \\
\hline \multirow[t]{2}{*}{ Alzheimer disease (AD) } & CHIT1 \\
\hline & Both CSF levels and enzymatic activity are $\uparrow$ in patients with AD compared with no dementia controls ${ }^{\mathrm{e} 6-\mathrm{e} 48}$ \\
\hline \multirow{8}{*}{$\begin{array}{l}\text { Amyotrophic lateral } \\
\text { sclerosis (ALS) }\end{array}$} & CHI3L2 \\
\hline & Levels are $\uparrow$ in patients with ALS vs ALS mimics and healthy controls ${ }^{\mathrm{e} 18, \mathrm{e} 53}$ \\
\hline & Correlation of CSF levels with disease progression rate ${ }^{e 53}$ \\
\hline & Upregulation in the motor cortex of patients with sporadic ALS e19 \\
\hline & CHIT1 \\
\hline & Levels are $\uparrow$ in patients with ALS vs ALS mimics, disease controls, and healthy controls ${ }^{56, e 18, e 53-\mathrm{e} 58}$ \\
\hline & Controversial results as prognostic biomarker \\
\hline & Expressed in the corticospinal tract of patients with ALS and colocalized with microglial and phagocytic markers ${ }^{56}$ \\
\hline \multirow[t]{4}{*}{ Stroke } & CHIT1 \\
\hline & $\begin{array}{l}\text { Patients with acute stroke exhibit higher baseline plasma chitinolytic activity compared with healthy controls but with no } \\
\text { prognostic value in long-term clinical outcome } \text { e64 }^{\text {a }}\end{array}$ \\
\hline & Association of low levels of plasma chitinolytic activity with short-term clinical improvement ${ }^{\mathrm{e} 4}$ \\
\hline & Correlation of plasma chitinolytic activity with stroke severity ${ }^{\mathrm{e} 65}$ \\
\hline \multirow[t]{2}{*}{ Traumatic brain injury } & CHIT1 \\
\hline & Upregulated in the contusional and pericontusional area ${ }^{\mathrm{e} 78}$ \\
\hline \multirow{2}{*}{$\begin{array}{l}\text { Creutzfeld-Jakob disease } \\
\text { (CJD) }\end{array}$} & CHIT1 \\
\hline & Levels are $\uparrow$ in patients with CJD vs controls ${ }^{\mathrm{e} 80}$ \\
\hline
\end{tabular}

Abbreviations: CHI3L2 = chitinase-3-like 2; CHIT1 = chitotriosidase; RRMS = relapsing-remitting MS; SPMS = secondary progressive MS .

microglial activation. ${ }^{\text {e10 }}$ Similarly, CHI3L1 KO mice presented more severe pathology and more pronounced reactive gliosis after cortical controlled impact than their WT littermates, thus supporting a role of CHI3L1 modulating astrocytic and microglial reactive gliosis. ${ }^{\text {e11 }}$ There are discrepant results regarding experimental autoimmune encephalomyelitis (EAE) model in CHI3L1 KO mice. Although Bonneh-Barkay et al. described an exacerbation of clinical EAE, inflammation, gliosis, and demyelination in CHI3L1 KO mice, ${ }^{\text {e12 }}$ Cantó et al. reported no differences of EAE course and gliosis between CHI3L1 KO mice and their WT littermates. ${ }^{\text {el3 }}$ Furthermore, treatment of $A \beta_{1-}$ 42 -infused mice, a model of AD, with K284-6111, a CHI3L1 inhibitor, resulted in decreased neuroinflammation and a memory recovery effect. ${ }^{\text {el4 }}$

All these data taken along underline the complexity of the CHI3L1 signaling networks in the CNS. Further investigation is needed to elucidate CHI3L1 signaling in the CNS and its disease-specific roles.

Little is known about $\mathrm{CHI} 3 \mathrm{~L} 2$ physiologic and pathologic role in the CNS. Increased CHI3L2 expression or CSF levels have been reported in various neuroinflammatory conditions. ${ }^{\text {e15- }}$ ${ }^{\mathrm{e} 19}$ However, CHI3L2 role in the CNS pathology remains obscure.

\section{Chitinases and CLP as biomarkers of neurologic and psychiatric disorders}

\section{MS}

MS is a neurodegenerative immune-mediated disorder of the CNS and one of the leading causes of nontraumatic neurologic disability among young adults. ${ }^{\mathrm{e} 20, \mathrm{e} 21}$ Considering the 
high degree of heterogeneity that characterizes the disease, there is a strong need for biomarkers that reliably capture the different aspects of MS heterogeneity and help in the development of a personalized medicine based on a better understanding of disease diagnosis, stratification, and prediction of disease course and response to therapies. ${ }^{\text {e22 }}$

The majority of chitinase studies in patients with MS measured CHI3L1 and were conducted in the CSF, although few studies also determined CHI3L1 levels in peripheral blood samples. Studies conducted at the time of the first neurologic event suggestive of CNS demyelination or clinically isolated syndrome (CIS) have pointed to a prognostic role of CHI3L1 in the early phases of the disease. In this context, high CSF levels at the time of the CIS have been associated with a higher risk of conversion to $\mathrm{MS}^{\mathrm{e} 15, \mathrm{e} 23-\mathrm{e} 25}$ and also with an increased risk for the development of neurologic disability. ${ }^{\text {e23,e25 }}$

In patients with relapsing-remitting MS (RRMS), CSF CHI3L1 levels were found to correlate with disease activity, and levels were significantly increased in patients at the time of clinical relapses compared with patients in remission and also correlated with a higher number of contrast-enhancing lesions in the brain MRI. ${ }^{\text {26 }}$ Comparison of CHI3L1 levels between patients with different clinical forms revealed significantly higher levels in patients with progressive forms of the disease (secondary and primary progressive MS - SPMS and PPMS, respectively) in relation to patients with RRMS and CIS, and these findings were observed both in samples from the CSF and peripheral blood (serum and plasma). ${ }^{\mathrm{e} 15, \mathrm{e} 27, \mathrm{e} 28}$ In patients with RRMS, high CSF CHI3L1 levels were an independent predictor of neurologic disability worsening and also of progression to an SPMS phase of the disease. ${ }^{\text {e28 }}$ In patients with CIS and RRMS, levels of CSF CHI3L1 were significantly associated with brain volume loss evaluated by the brain parenchymal fraction change during follow-up. ${ }^{\text {e23,e29 }}$ CSF CHI3L1 levels can also be modified by MS therapies, and for instance levels were significantly reduced by the effect of natalizumab and fingolimod, ${ }^{\mathrm{e} 30, \mathrm{e} 31}$ and in another study serum CHI3L1 levels were associated with the response to IFN $\beta$, ${ }^{\mathrm{e} 2} \mathrm{CSF}$ CHI3L1 levels were found to correlate with CSF levels of other neurodegenerative and inflammatory biomarkers such as the neurofilament light chain, CXCL13, or MMP-9. ${ }^{\text {e28,e33 }}$

CHI3L1 expression was observed in chronic active lesions from patients with MS, but it was absent in brain tissue from non-neurologic controls. Within CNS lesions, CHI3L1 expression was present both in macrophages/microglial cells and astrocytes, with an important contribution of astrocytes to CHI3L1 expression in those chronic active lesions classified as having high inflammatory activity. ${ }^{\text {e33 }}$

Regarding other chitinases, in 1 study, high CSF CHI3L2 levels were associated with an increased risk of MS in patients with CIS, ${ }^{\text {e16 }}$ although another study failed to find an association between high CSF or serum CHI3L2 levels and later conversion to $\mathrm{MS}^{\text {e15 }}$ In contrast to $\mathrm{CHI} 3 \mathrm{~L} 1, \mathrm{CSF}$ CHI3L2 levels were found to be significantly increased in patients with RRMS compared with patients with progressive MS. ${ }^{\text {e15 }}$ In a recent study, CSF CHIT1 levels were found to correlate with long-term disease activity. ${ }^{\text {e34 }}$

\section{Alzheimer disease}

Alzheimer disease is the most common cause of dementia in the Western world and causes a progressive impairment of cognitive functions. ${ }^{\text {e35 }}$ Neuroinflammation can also be detected in the brain from the early stages of the disease, and a number of inflammatory biomarkers have been investigated in patients with Alzheimer disease. ${ }^{\text {e36 }}$

Similar to MS, the majority of chitinase studies in patients with Alzheimer disease measured CHI3L1 levels and were conducted in CSF samples from patients. Overall, these studies reflect the utility of $\mathrm{CHI} 3 \mathrm{~L} 1$ as a diagnostic and prognostic biomarker in Alzheimer disease. In an initial proteomic study using 2 dimensional difference gel electrophoresis and liquid chromatography tandem mass spectrometry, CSF CHI3L1 was first proposed as a potential biomarker in patients with Alzheimer disease. ${ }^{\text {37 }}$ Regarding its prognostic role, CSF CHI3L1 levels are usually found increased in preclinical, prodromal, and demential cases of Alzheimer disease compared with cognitively normal individuals. ${ }^{\text {e38-e41 }}$ CHI3L1 also behaves as a predictive biomarker of Alzheimer disease, insomuch as high CSF CHI3L1 levels were found to be associated with an increased risk of future development of Alzheimer disease in cognitively unimpaired individuals or patients with mild cognitive impairment (MCI) compared with patients with stable MCI. ${ }^{\text {e37,e39,e42 }}$ CSF CHI3L1 levels have been reported to increase longitudinally during the stages of MCI and Alzheimer disease, but not in cognitively normal individuals, suggesting that this biomarker might also be useful for disease monitoring. ${ }^{\text {et }}$ High levels of CSF CHI3L1 have also been associated with brain MRI changes such as cortical thinning in parietal areas including precuneus, posterior cingulate, and superior parietal cortices ${ }^{\mathrm{e} 9}$ and also in temporal areas. ${ }^{\text {e43 }}$

Regarding the role of CHI3L1 as a diagnostic biomarker, several studies aimed to distinguish Alzheimer disease from other dementing illnesses, with controversial results for the frontotemporal dementia (FTD). Whereas some studies reported no differences between patients with Alzheimer disease and FTD, ${ }^{\text {e38,e40 }}$ others found either increased CHI3L1 levels in patients with FTD compared with patients with Alzheimer disease ${ }^{\mathrm{e} 37}$ or increased levels of CHI3L1 in patients with Alzheimer disease vs FTD. ${ }^{41}$ However, classification of patients with FTD into pathologic phenotypes revealed higher CSF CHI3L1 levels in the tau-positive FTD subtype compared with patients with Alzheimer disease. ${ }^{\mathrm{e} 44}$ Comparisons of CHI3L1 levels between Alzheimer disease and $\alpha$-synucleinopathies revealed significantly higher $\mathrm{CHI} 3 \mathrm{~L} 1$ levels in patients with Alzheimer disease compared with 


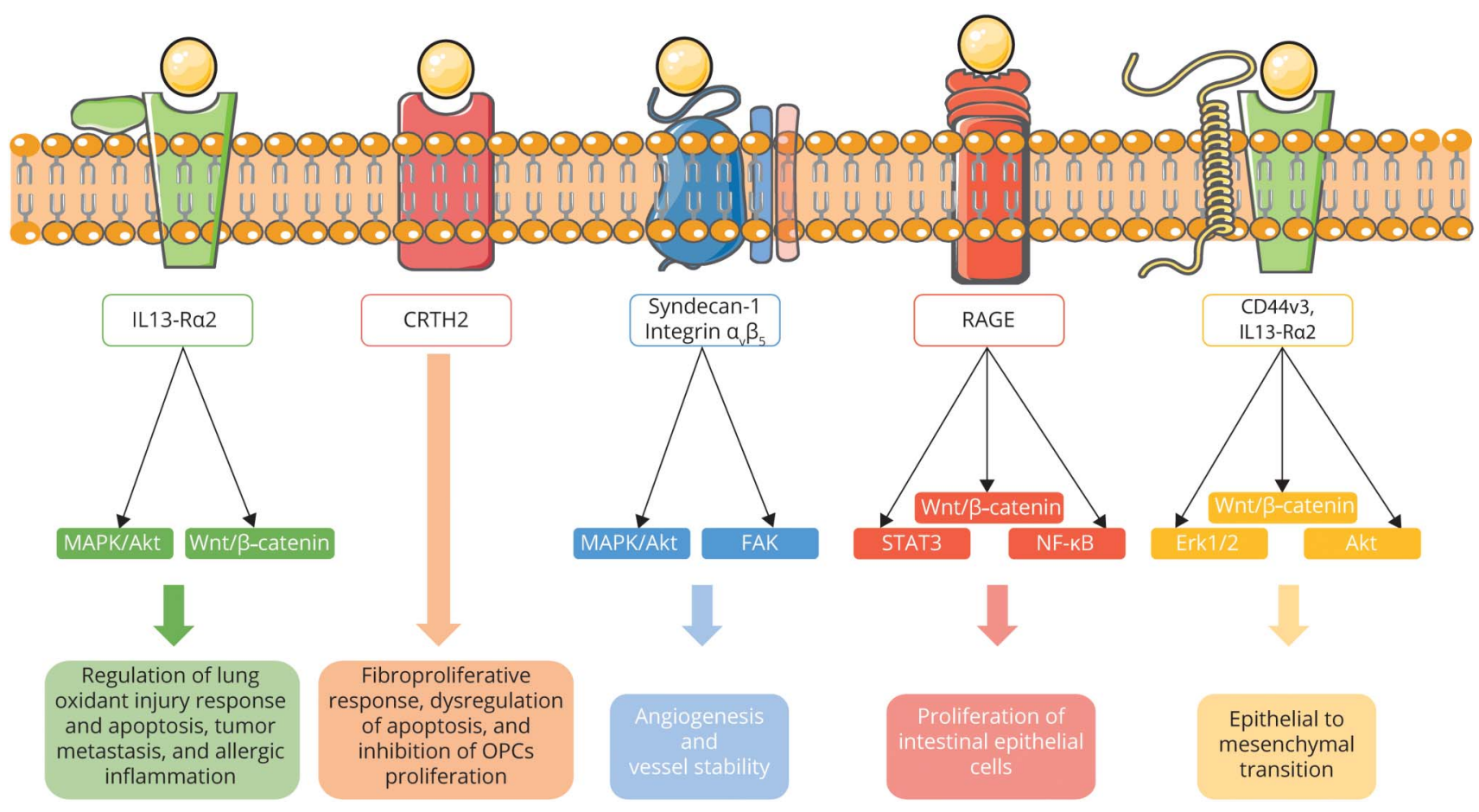

The interaction of CHI3L1 with IL-13Ra2 and TMEM219 activates several intracellular signaling pathways such as MAPK, protein kinase B/Akt, and Wnt/ $\beta$-catenin, leading to diverse cellular outcomes including regulation of lung oxidant injury response, apoptosis, tumor metastasis, and allergic inflammation. CHI3L1 binding to CRTH2 mediates a fibroproliferative response and dysregulation of apoptosis in Hermansky-Pudlak syndrome and an inhibition of OPCs proliferation in a human cellular model. CHI3L1 can induce angiogenesis by binding to the side chain molecules of syndecan-1, then inducing coordination with integrin av $\beta 5$ and activating downstream FAK and MAPK. CHI3L1 interaction with RAGE activates STAT6, Wnt/ $\beta$-catenin and NF-KB and promotes proliferation of intestinal epithelial cells. Last, CHI3L1 interacts with CD44v3 and IL-13Ra2 inducing epithelial to mesenchymal transition through Erk1/2, Wnt/ $\beta$-catenin, and Akt signaling. CHI3L1 = chitinase-3-like 1; CRTH2 = prostaglandin D2 receptor 2; Erk = extracellular signal-regulated kinase; FAK = focal adhesion kinase; IL-13Ra2 = interleukin-13 receptor a2; MAPK = mitogen-activated protein kinase; OPC = oligodendrocyte progenitor cell; TMEM219 = transmembrane protein 219.

patients with Parkinson disease (PD) dementia or dementia with Lewy bodies. ${ }^{\text {e38,e45 }}$

CSF CHI3L1 levels have been found to significantly correlate with other CSF biomarkers in patients with $\mathrm{Alz}$ heimer disease. In this context, strong correlations were observed between CSF CHI3L1 levels and biomarkers of neuronal degeneration such as phospho-tau or total tau. $^{\text {e39,e43 }}$ Similarly, CHI3L1 was found to correlate with $\beta$-amyloid. ${ }^{\text {e38 }}$ No differences have been observed in CHI3L1 levels between APOE\&4 allele carriers and noncarriers. $^{\text {e38,e } 45}$

Studies measuring CHIT1 revealed significantly higher CSF CHIT1 levels in patients with Alzheimer disease compared with cognitively healthy controls. ${ }^{\text {et6 }}$ Similarly, enzymatic activity of CHIT 1 was also found increased in the CSF of patients with Alzheimer disease compared with no dementia controls. ${ }^{\text {e4,e48 }}$

In the CNS, CHI3L1 expression is mainly found in a subset of astrocytes in the frontal cortex from patients with Alzheimer disease, sometimes in close apposition to amyloid plaques but also independent of plaque pathology. ${ }^{\text {e1,e49,e50 }}$

\section{Amyotrophic lateral sclerosis}

Amyotrophic lateral sclerosis (ALS) is a fatal neurodegenerative disease characterized by the selective neurodegeneration and death of the upper and lower motor neurons, usually leading to death within 3-5 years from the symptom onset. ${ }^{\text {e51 }}$ Although the mechanisms are not yet understood, activation of a neuroinflammatory response and reactive gliosis are prominent features of ALS and are related to disease progression. ${ }^{\mathrm{e} 52}$ There is growing interest in the modulation of neuroinflammation as a potential therapeutic target in ALS. Therefore, biomarkers that track neuroinflammatory activity are necessary to stratify patients for clinical trials and monitoring treatment response.

Chitinases have been shown to play roles as diagnostic and prognostic biomarkers in ALS. As diagnostic biomarkers, studies using proteomic ${ }^{\mathrm{e} 53, \mathrm{e} 54}$ and immunetargeted $^{56, \mathrm{e} 18, \mathrm{e} 55-57}$ approaches reported significantly increased CSF CHIT1, CHI3L1, and CHI3L2 levels in patients with ALS compared with healthy controls, ALS mimics (patients without ALS with motor weakness in whom ALS was considered in the differential diagnosis), or other disease controls. Diagnostic performance of CHIT1, CHI3L1, and CHI3L2 distinguishing patients with ALS from ALS mimics 
has also been acceptable, ${ }^{\text {e18,e53 }}$ although with discrepant results. $^{\text {e56 }}$

Several pieces of evidence support a prognostic value for CHIT1, CHI3L1, and CHI3L2 in ALS. A number of studies showed that CHIT1, ${ }^{\text {e53,e57,e58 }} \mathrm{CHI3L1}$, $53, \mathrm{e} 57, \mathrm{e} 59, \mathrm{e} 60$ and CHI3L2 ${ }^{\text {e53 }}$ CSF levels correlated with disease progression rates, and higher CSF baseline levels of CHIT1 and CHI3L1 were associated with shorter survival time. ${ }^{56, \mathrm{e} 53, \mathrm{e} 56, \mathrm{e} 60}$ However, other studies failed to find a prognostic value for CHIT1 and CHI3L1. ${ }^{\text {e18,e55 }}$

Studies evaluating longitudinal profiles of CSF chitinase levels obtained by repeated lumbar punctures revealed either constant CSF CHIT1 or CHI3L1 levels over time ${ }^{78,117}$ or slightly increased CSF CHI3L1 levels during the disease. ${ }^{\text {e53,e56 }}$

Cognitive and behavioral impairment is present in up to $30 \%$ of patients with ALS. ${ }^{\text {61 }} \mathrm{CHI} 3 \mathrm{~L} 1$, but not CHIT1 or CHI3L2, has been associated with cognitive dysfunction in patients with ALS. ${ }^{\text {e18 }}$

CSF CHI3L1 levels were found to strongly correlate with biomarkers of neurodegeneration such as the neurofilament light chain and the phosphorylated neurofilament heavy chain protein. $^{\text {e18,e56,e57 }}$

CNS expression studies showed significant upregulation of CHI3L1 and CHI3L2 in the motor cortex of patients with sporadic ALS compared with neurologically healthy controls, and their expression levels were correlated with the survival time from date of onset. ${ }^{\text {e19 }}$ Other studies showed significantly increased expression of CHI3L1 in the anterior horn of the spinal cord in patients with sporadic

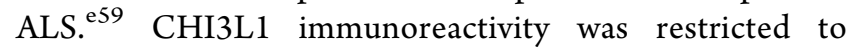
GFAP-positive astrocytes in the frontal cortex and spinal cord of patients with ALS, indicating that reactive astrocytes are the main CNS cell source of CHI3L1 expression. ${ }^{\text {e57,e59 }}$ CHIT1 immunostaining was found to colocalize with Ibal (microglial marker) and CD68 (phagocytic activity marker)-positive cells in the postmortem spinal cord of patients with ALS. ${ }^{56}$ CHIT 1-immunoreactive cells were present mainly in the corticospinal tract of patients with ALS but not healthy controls, Creutzfeldt-Jakob disease (CJD), or Alzheimer disease patients, thereby suggesting a disease-specific CHIT 1 expression pattern in ALS. 56

All these data taken together suggest that CHI3L1 seems to be a promising biomarker of pathogenic glial activation in ALS, and it may be useful as a surrogate for future treatments targeting neuroinflammation. Regarding CHIT 1, the fact that homozygous carriers of a CHIT 1 polymorphism, which leads to diminished CHIT1 expression, do not exhibit decreased ALS severity supports the hypothesis that CHIT1 is rather a neuroinflammatory marker than an active contributor to ALS pathogenesis. ${ }^{\text {e58 }}$

\section{Stroke}

Ischemic stroke is a leading cause of disability and death in the world. ${ }^{\text {e62 }}$ Once the cerebral arteria is occluded, a cascade of pathologic events starts. Necroptotic or apoptotic cell death, oxidative stress, reactive gliosis, and migration of peripheral immune cells into the brain parenchyma are features of ischemic brain damage. ${ }^{\text {e62 }}$ Ischemic stroke is often related to atherosclerosis, an inflammatory condition in which monocytes infiltrate into the vessel wall and then differentiate into lipid-laden macrophages. Serum CHIT1 activity has been proposed as a biomarker of atherosclerosis, and its activity was increased in patients with atherosclerosis and correlated with the extension of the atherosclerotic lesion. ${ }^{17, \mathrm{e} 63}$ Patients with acute stroke were reported to have significantly higher baseline plasma CHIT 1 enzymatic activity compared with healthy controls, and low levels of plasma chitinolytic activity were associated with short-term clinical improvement. ${ }^{\text {e64 }}$ However, the latter had no prognostic value in long-term clinical outcomes. ${ }^{\text {64 }}$ Besides, CHIT1 plasmatic activity was reported to correlate directly with stroke severity, independent of preexisting inflammatory conditions. ${ }^{\text {e65 }}$

Similarly, serum CHI3L1 levels have been found to correlate with infarct volume, stroke severity, and functional outcome in patients with acute ischemic stroke with a CHI3L1 peak on the second day after symptom onset. ${ }^{\text {e66 }}$ Moreover, serum CHI3L1 has been described as an independent biomarker to predict the clinical outcome of large-artery atherosclerotic stroke, and high CHI3L1 levels were associated with poor clinical outcome. ${ }^{\text {e67 }}$ Several prospective epidemiologic large-scale studies reported that elevated plasma baseline CHI3L1 levels are associated with an increased risk of ischemic stroke. ${ }^{\text {e68-e71 }}$ Nevertheless, further investigation is needed to elucidate whether circulating $\mathrm{CHI} 3 \mathrm{~L} 1$ has a causative role in ischemic stroke or it is a nonspecific marker of inflammation.

Comparison of CHI3L1 transcription in acute, subacute, and chronic infarcted human brain samples revealed a transient expression at the acute stage (3-5 days poststroke) mostly in astrocytes proximal to the injury site. ${ }^{60}$ It would thus appear that acute inflammation induces CHI3L1 expression, and when inflammation resolves, CHI3L1 expression diminishes.

\section{Traumatic brain injury}

Traumatic brain injury is one of the leading causes of disability and death worldwide. ${ }^{\mathrm{e} 2}$ The primary mechanical insult is followed by acute neuroinflammation that leads to astrocyte and microglial activation and increased secretion of immune mediators. ${ }^{\text {e73,e74 }}$ Temporal profiles of CSF CHI3L1 levels following traumatic brain injury showed significantly elevated CHI3L1 levels after the first day compared with healthy controls, and levels reached a peak at 4 days posttraumatic brain injury declining subsequently at days 5 and 6 after injury. CHI3L1 levels were strongly correlated with levels of proinflammatory cytokines in the 


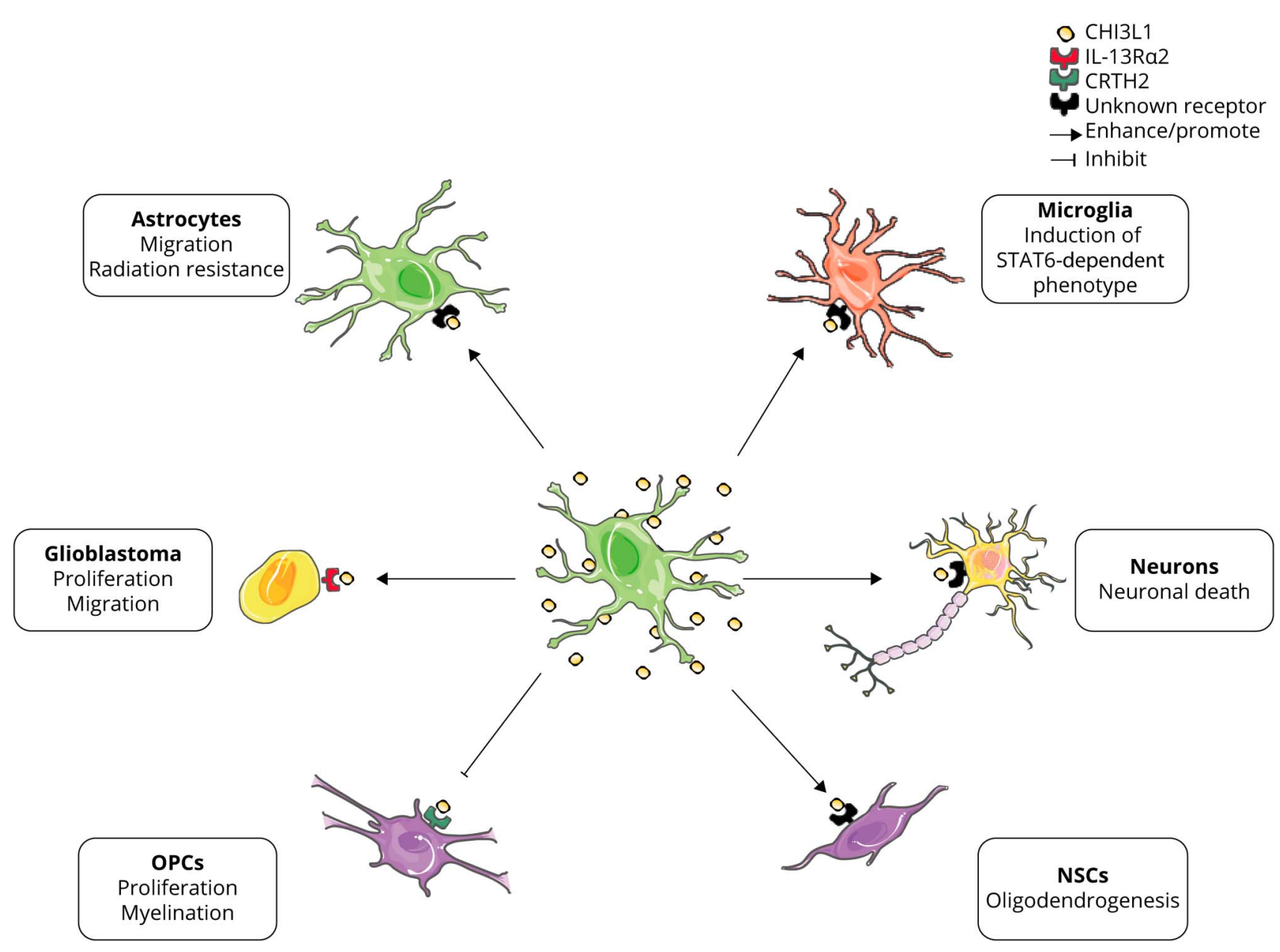

Astrocytes are the main source of CHI3L1 in the CNS. Once secreted, CHI3L1 can induce multiple responses depending on the cellular type and context. In vitro studies reported that (1) CHI3L1 increases migration and radiation resistance of cultured human astrocytes; (2) CHI3L1 expression is induced in glioblastomaassociated astrocytes promoting tumor proliferation and migration through IL-13Ra2 signaling; (3) CHI3L1 inhibits proliferation and myelination in OPCs and (4) enhances oligodendrogenesis of NSCS; and (5) CHI3L1 is neurotoxic in mouse primary cultured neurons. In vivo study: CHI3L1 KO mice exhibit decreased STAT6 microglial activation after CCI. CCI = cortical controlled impact; CHI3L1 = chitinase-3-like 1; CRTH2 = prostaglandin D2 receptor 2; IL-13Ra2 = interleukin13 receptor a2; NSC = neural stem cell; OPC = oligodendrocyte progenitor cell.

CSF such as IL-1 $\beta, T N F \alpha$, and C-reactive protein. ${ }^{\text {e75 }}$ Of note, patients who died due to traumatic brain injury tended to have elevated CSF CHI3L1 levels compared with patients who survived, suggesting that increased CHI3L1 levels may be predictive of worse survival outcomes. ${ }^{\text {75 }}$

Serum levels of CHI3L1 together with serum amyloid A1, $\mathrm{C}$-reactive protein, and $\mathrm{S} 100 \beta$ showed the most robust association with level of consciousness following traumatic brain injury. ${ }^{\text {e76 }}$ Furthermore, levels correlated significantly with the extent of traumatic intracranial lesions and had good potential to identify bleeding in several intracranial compartments, and for instance, CHI3L1 was the best biomarker for subdural blood collection detection. ${ }^{\mathrm{e} 76}$ Altogether, these findings point to CHI3L1 as a promising biomarker to determine the neurologic severity of patients with traumatic brain injury.
In patients with persistent post-concussion syndrome (PCS) secondary to repetitive concussive traumatic brain injury, CSF CHI3L1 levels were significantly increased compared with controls and correlated with symptom severity and the lifetime number of concussions. ${ }^{\mathrm{e} 77}$ These findings suggest that PCS may be associated with biomarker evidence of astroglial activation.

Proteomic analysis of craniotomy and postmortem human brain samples revealed that both CHI3L1 and CHIT 1 were upregulated in the contusion and pericontusional area. ${ }^{\text {e78 }}$ In this study, additional immunohistochemistries to identify the chitinase cellular source of CNS expression were not performed; however, in a rat model of traumatic brain injury, CHI3L1 expression was found to be associated with reactive astrocytes in the pericontusional cortex starting 1 day after the insult and remaining stable for several days, thus paralleling the findings of temporal profiles of CSF 
CHI3L1 levels observed in patients with traumatic brain injury. $^{\text {e75 }}$

\section{Creutzfeldt-Jakob disease}

CJD is a fatal neurodegenerative disease caused by misfolded transmissible proteinaceous particles named prions ${ }^{\mathrm{e} 79}$. Studies of chitinases in CJD evaluated their potential as diagnostic biomarkers distinguishing CJD from other neurodegenerative disorders. In a recent study measuring glial markers (CHI3L1, CHIT1, and GFAP) in neurodegenerative dementias characterized by protein misfolding and aggregation, CSF CHI3L1 levels were significantly elevated in patients with sporadic CJD compared with patients with Alzheimer disease, FTD, and controls without clinical or neuroradiologic evidence of CNS disease. ${ }^{e 80}$ In contrast, although CSF CHIT1 and GFAP levels were elevated in patients with CJD vs controls, they could not discriminate between different neurodegenerative dementias. ${ }^{\text {e80 }}$ Similar findings were observed in another study, where CSF CHI3L1 levels were reported significantly increased in patients with sporadic CJD compared with neurologic controls and patients with other neurodegenerative dementias, and levels significantly correlated with tau, a marker of axonal degeneration. ${ }^{49}$ Studies in peripheral blood also revealed significantly increased plasma CHI3L1 levels in patients with CJD compared with other neurodegenerative dementias, neurologic controls, and healthy controls. ${ }^{\text {e81 }}$ All these findings underscore the presence of an important neuroinflammatory response in patients with prion disease.

In CNS expression studies, CHI3L1 was reported to be highly upregulated in sporadic CJD frontal cortex and cerebellum, and it was positively correlated with GFAP expression. ${ }^{\text {e49 }}$ Immunohistochemistry analysis revealed a specific pattern of CHI3L1 distribution in sporadic CJD: although in control brains, CHI3L1 immunoreactivity was mainly restricted to fibrillar astrocytes in the white matter, the sporadic CJD brains showed $\mathrm{CHI} 3 \mathrm{~L} 1$ expression in reactive protoplasmic and perivascular astrocytes and also an increased signal in fibrillar astrocytes in the white matter. ${ }^{\text {e49 }}$

\section{Parkinson disease}

$\mathrm{PD}$ is a common neurodegenerative condition mainly characterized by the death of dopaminergic neurons in the substantia nigra and the presence of intracellular fibrillar aggregates of $\alpha$-synuclein. ${ }^{\mathrm{e} 82}$ Neuroinflammation seems also to play a role in disease pathogenesis and contribute to neurodegeneration. ${ }^{\mathrm{e} 83, \mathrm{e} 84}$ Studies of chitinases in patients with PD are scarce. In a longitudinal study with lumbar puncture performed at baseline and after 2 years of followup, CSF CHI3L1 levels were significantly increased over time in patients with both short and long disease duration. ${ }^{\text {e85 }}$ Furthermore, the increase in CHI3L1 levels significantly correlated with worsening of cognitive function. ${ }^{\mathrm{e} 85}$ Other studies revealed either no differences in CSF CHI3L1, CHI3L2, and CHIT1 levels between patients with PD and controls $^{\mathrm{e} 45, \mathrm{e} 53}$ or lower CHI3L1 levels in patients vs controls. $^{\text {e86 }}$ In this context, more studies of chitinases are needed in patients with PD to better understand their potential role in disease pathogenesis.

\section{HIV-associated dementia}

Cognitive impairment in patients with HIV can range from asymptomatic neurocognitive impairment to HIV-associated dementia. $^{\text {e87 }}$ Astrocytes are known to play a role in the pathogenesis of HIV-associated dementia. ${ }^{\text {e88 }}$ In 1 study, CSF CHI3L1 levels were found to be significantly increased in patients with HIV-associated dementia compared with untreated neuroasymptomatic patients with HIV irrespective of $\mathrm{CD}^{+} \mathrm{T}$ cell counts, patients with HIV under antiretroviral treatment, and HIV-negative individuals. ${ }^{\text {e89 }}$ Furthermore, CSF CHI3L1 levels correlated with CSF neurofilament light chain. ${ }^{\text {e89 }}$ Similar to PD, more chitinase studies are necessary in patients with HIV-associated dementia, although it should be taken into account that the prevalence of this condition has been drastically reduced in the post-antiretroviral treatment era. $^{\text {e87 }}$

\section{Psychiatric diseases}

Schizophrenia is a complex major mental disorder affecting $1 \%$ of the population worldwide. ${ }^{\text {e90 }}$ Schizophrenia etiology is multifactorial, involving both genetic and environmental factors. ${ }^{\text {e91 }}$ A first genetic association study provided evidence of an association between functional variants at the CHI3L1 locus and schizophrenia genetic risk. ${ }^{\text {e92 }}$ The genetic variations of CHI3L1 may influence pathologic processes taking place in schizophrenia development, thus being involved in the disease susceptibility. Compelling evidence sets a role for innate immune activation in schizophrenia. ${ }^{\text {e93 }}$ First-episode psychosis patients showed a higher number of blood monocytes and increased plasma levels of CHI3L1 and monocyte chemoattractant protein 1 compared with controls. ${ }^{\text {e94 }}$ However, caution must be applied to interpret these results owing to the small sample size. Gene expression analysis of postmortem brain tissue revealed an upregulation of CHI3L1 in the hippocampus ${ }^{\text {e95 }}$ and prefrontal cortex ${ }^{\mathrm{e} 6}$ of patients with schizophrenia compared with controls suggesting a neuroinflammatory response. Nevertheless, these studies are limited to differential gene expression and do not assess the CHI3L1 source in the schizophrenic brain.

Bipolar disorder is a chronic psychiatric disease characterized by recurrent episodes of depression and mania that affects more than $1 \%$ of worldwide population. ${ }^{\text {e97 }}$ Systemic inflammation and neuroinflammation are gaining attention as key players in bipolar disorder pathogenesis. ${ }^{\text {e98 }}$ In this regard, both CSF and serum CHI3L1 levels were reported to be significantly higher in patients with bipolar disorder than controls. ${ }^{\mathrm{e} 99}$ Moreover, CSF CHI3L1 levels have been associated with cognitive impairment in patients with euthymic bipolar disorder. ${ }^{\text {e100 }}$ In a study investigating the 
relationship between baseline CSF CHI3L1 levels and longterm clinical outcomes, CHI3L1 was found to be negatively associated with maniac/hypomaniac or psychotic episodes. ${ }^{\text {e101 }}$ Although the association survived correction for multiple testing, this result should be interpreted with caution because of a possible collinearity issue reported by the authors.

\section{Future perspectives of chitinase and CLP studies in neurologic disorders}

Based on the studies outlined in the previous section, chitinases and CLPs, particularly CHI3L1, are playing roles as biomarkers in a wide range of neurologic disorders in which there is a neuroinflammatory component as part of their pathophysiology. This inflammatory component will result in astrocyte activation, which ultimately seems to be the cell involved in chitinase secretion, although a contribution of microglia cannot be ruled out as some studies also pointed to a microglial source of chitinases. A number of considerations in relation to chitinases and CLPs studies are the following: (1) Depending on the neurologic disease and the outcome analyzed, there are sometimes discrepancies in the results. This has been and is still the rule in many biomarker studies, and chitinases are not an exception, and most likely reflects the complexity and heterogeneity of the neurologic conditions that are being evaluated. However, other factors such as preanalytical variability, insufficient sample size, or the use of different criteria to classify patients may also contribute to the discrepancies. (2) Although statistically significant, differences among groups in some studies are small and indicate important overlaps of CSF or blood chitinase levels between patients belonging to different categories. This aspect, which may also lead to discrepancies across studies, may be a limitation for the use of chitinases as diagnostic biomarkers. However, chitinase data may complement clinical and radiologic information or may be combined with other biomarkers to increase diagnostic accuracy. (3) Despite more studies are needed in this direction, chitinases probably have their greatest potential as prognostic biomarkers in neurologic disorders. In this context, the different studies outlined in the review have shown a more solid role for chitinases as prognostic biomarkers compared with their diagnostic potential, most likely reflecting the usually detrimental contribution of astrocytes to the pathophysiology of neurologic diseases. (4) In contrast to other biomarkers whose expression is more CNS specific, for instance neurofilaments, tau or GFAP, chitinases are secreted by a broad range of cells from peripheral compartments. In this context, there is an important contribution of blood monocytes/macrophages to chitinase levels measured in serum or plasma, and hence, blood chitinase levels may not be as informative as CSF levels to monitor the pathophysiologic changes taking place in the CNS of neurologic disorders. This is a limitation to the use of blood as a surrogate of CSF to measure chitinase levels in neurologic disorders (unlike the neurofilament light chain). (5) Finally, chitinases may be not only CSF secreted biomarkers that reflect the degree of astrocyte activation or injury but also they have the potential to become therapeutic targets that set the rationale for the design of new therapies. For instance, CHI3L1 has shown to be neurotoxic in a dosedependent manner. ${ }^{30, \mathrm{e} 9}$

In conclusion, although there are still several unknowns in the function of chitinases and CLPs in the CNS, they are promising candidates that are consolidating their role as diagnostic and prognostic biomarkers in a broad spectrum of inflammatory and neurodegenerative diseases. The potential for chitinases to become therapeutic targets certainly opens new avenues for future research in the field of biomarkers for neurologic disorders.

\section{Study funding}

No targeted funding reported.

\section{Disclosure}

No relevant disclosures. Go to Neurology.org/NN for full disclosures.

\section{Publication history}

Received by Neurology: Neuroimmunology \& Neuroinflammation August 7, 2020. Accepted in final form September 23, 2020.

\begin{tabular}{|c|c|c|}
\hline Name & Location & Contribution \\
\hline $\begin{array}{l}\text { Rucsanda } \\
\text { Pinteac, } \\
\text { MSc }\end{array}$ & $\begin{array}{l}\text { Centre d'Esclerosi Múltiple } \\
\text { de Catalunya (Cemcat), } \\
\text { Institut de Recerca, } \\
\text { Hospital Vall d'Hebron, } \\
\text { Barcelona, Spain }\end{array}$ & $\begin{array}{l}\text { Drafting/revising the } \\
\text { manuscript for content, } \\
\text { including medical writing } \\
\text { for content, and study } \\
\text { concept }\end{array}$ \\
\hline $\begin{array}{l}\text { Xavier } \\
\text { Montalban, } \\
\text { MD, PhD }\end{array}$ & $\begin{array}{l}\text { Centre d'Esclerosi Múltiple } \\
\text { de Catalunya (Cemcat), } \\
\text { Hospital Vall d'Hebron, } \\
\text { Barcelona, Spain }\end{array}$ & $\begin{array}{l}\text { Drafting/revising the } \\
\text { manuscript for content, } \\
\text { including medical writing } \\
\text { for content, and study } \\
\text { concept }\end{array}$ \\
\hline $\begin{array}{l}\text { Manuel } \\
\text { Comabella, } \\
\text { MD, PhD }\end{array}$ & $\begin{array}{l}\text { Centre d'Esclerosi Múltiple } \\
\text { de Catalunya (Cemcat), } \\
\text { Institut de Recerca, } \\
\text { Hospital Vall d'Hebron, } \\
\text { Barcelona, Spain }\end{array}$ & $\begin{array}{l}\text { Drafting/revising the } \\
\text { manuscript for content, } \\
\text { including medical writing } \\
\text { for content, and study } \\
\text { concept }\end{array}$ \\
\hline
\end{tabular}

\section{References}

1. Komi DEA, Sharma L, Dela Cruz CS. Chitin effect on inflammation and immune response. Clin Rev Allergy Immunol 2018;54:213-223.

2. Guan SP, Mok YK, Koo KN, Chu KL, Wong WS. Chitinases: biomarkers for human diseases. Protein Pept Lett 2009; 16:490-498.

3. Funkhouser JD, Aronson NN. Chitinase family GH18: evolutionary insights from the genomic history of a diverse protein family. BMC Evol Biol 2007; 7 : $1-16$.

4. Huang QS, Xie XL, Liang G, et al. The GH18 family of chitinases: their domain architectures, functions and evolutions. Glycobiology 2012;22:23-34.

5. Di Rosa M, Distefano G, Zorena K, Malaguarnera L. Chitinases and immunity: ancestral molecules with new functions. Immunobiology 2015;221:399-411. 
6. Li H, Greene LH. Sequence and structural analysis of the chitinase insertion domain reveals two conserved motifs involved in chitin-binding. PLoS One 2010;5:e8654

7. Moussian B Targeting Chitin-Containing Organisms [online]. Singapore: Springer; 2019. Available at: link.springer.com/10.1007/978-981-13-7318-3. Accessed May 5, 2020.

8. Bussink AP, Speijer D, Aerts JMFG, Boot RG. Evolution of mammalian chitinase(like) members of family 18 glycosyl hydrolases. Genetics 2007;177:959-970.

9. Patel S, Goyal A. Chitin and chitinase: role in pathogenicity, allergenicity and health. Int J Biol Macromol 2017;97:331-338.

10. Hollak CE, van Weely S, van Oers MH, Aerts JM. Marked elevation of plasma chitotriosidase activity. A novel hallmark of Gaucher disease. J Clin Invest 1994;93:1288-1292.

11. Boot RG, Renkema GH, Strijland A, van Zonneveld AJ, Aerts JM. Cloning of a cDNA encoding chitotriosidase, a human chitinase produced by macrophages. J Biol Chem 1995;270:26252-26256

12. Di Rosa M, Musumeci M, Scuto A, Musumeci S, Malaguarnera L. Effect of interferon-gamma, interleukin-10, lipopolysaccharide and tumor necrosis factoralpha on chitotriosidase synthesis in human macrophages. Clin Chem Lab Med 2005;43:499-502.

13. Malaguarnera L, Musumeci M, Di Rosa M, Scuto A, Musumeci S. Interferon-gamma, tumor necrosis factor-alpha, and lipopolysaccharide promote chitotriosidase gene expression in human macrophages. J Clin Lab Anal 2005;19:128-132.

14. Di Rosa M, Malaguarnera G, De Gregorio C, Drago F, Malaguarnera L. Evaluation of CHI3L-1 and CHIT-1 expression in differentiated and polarized macrophages. Inflammation 2013;36:482-492.

15. Kanneganti M, Kamba A, Mizoguchi E. Role of chitotriosidase (Chitinase 1) under normal and disease conditions. J Epithel Biol Pharmacol 2012;5:1-9.

16. Di Rosa M, Tibullo D, Cambria D, et al. Chitotriosidase expression during monocytederived dendritic cells differentiation and maturation. Inflammation 2015;38: 2082-2091.

17. Artieda M, Cenarro A, Ganan A, et al. Serum chitotriosidase activity is increased in subjects with atherosclerosis disease. Arterioscler Thromb Vasc Biol 2003;23: $1645-1652$.

18. Bargagli E, Maggiorelli C, Rottoli P. Human chitotriosidase: a potential new marker of sarcoidosis severity. Respiration 2008;76:234-238.

19. Comabella M, Dominguez C, Rio J, et al. Plasma chitotriosidase activity in multiple sclerosis. Clin Immunol 2009;131:216-222.

20. Barone R, Simpore J, Malaguarnera L, Pignatelli S, Musumeci S. Plasma chitotriosidase activity in acute Plasmodium falciparum malaria. Clin Chim Acta 2003;331: 79-85.

21. Boot RG, Blommaart EF, Swart E, et al. Identification of a novel acidic mammalian chitinase distinct from chitotriosidase. J Biol Chem 2001;276:6770-6778.

22. Bussink AP, Vreede J, Aerts JMFG, Boot RG. A single histidine residue modulates enzymatic activity in acidic mammalian chitinase. FEBS Lett 2008;582: 931-935.

23. Seibold MA, Reese TA, Choudhry S, et al. Differential enzymatic activity of common haplotypic versions of the human acidic mammalian chitinase protein. J Biol Chem 2009;284:19650-19658.

24. Reese TA, Liang HE, Tager AM, et al. Chitin induces accumulation in tissue of innate immune cells associated with allergy. Nature 2007;447:92-96.

25. Zhu Z, Zheng T, Homer RJ, et al. Acidic mammalian chitinase in asthmatic Th2 inflammation and IL-13 pathway activation. Science 2004;304:1678-1682.

26. Kognole AA, Payne CM. Inhibition of mammalian glycoprotein YKL-40. J Biol Chem 2017;292:2624-2636

27. Hakala BE, White C, Recklies $\mathrm{AD}$. Human cartilage gp-39, a major secretory product of articular chondrocytes and synovial cells, is a mammalian member of a chitinase protein family. J Biol Chem 1993;268:25803-25810.

28. Sohn MH, Kozhich AA, Matsuura H, et al. Role of breast regression protein 39 (BRP39)/chitinase 3-like-1 in Th2 and IL-13-induced tissue responses and apoptosis. J Exp Med 2009;206:1149-1166.

29. Di Rosa M, Tibullo D, Saccone S, et al. CHI3L1 nuclear localization in monocyte derived dendritic cells [online]. Immunobiology 2016;221:347-356.

30. Huang C, Huang B, Bi F, et al. Profiling the genes affected by pathogenic TDP-43 in astrocytes. J Neurochem 2014;129:932-939.

31. He CH, Lee CG, DelaCruz CS, et al. Chitinase 3-like 1 regulates cellular and tissue responses via IL-13 receptor $\alpha 2$. Cell Rep 2013;4:830-841.

32. Lee CM, He CH, Nour AM, et al. IL-13Ra2 uses TMEM219 in chitinase 3-like-1induced signalling and effector responses. Nat Commun 2016;7:1-12.

33. Chen Y, Zhang S, Wang $\mathrm{Q}$, Zhang X. Tumor-recruited M2 macrophages promote gastric and breast cancer metastasis via M2 macrophage-secreted CHI3L1 protein. J Hematol Oncol 2017;10:1-13.

34. Zhou Y, He CH, Herzog EL, et al. Chitinase 3-like-1 and its receptors in HermanskyPudlak syndrome-associated lung disease. J Clin Invest 2015;125:3178-3192.
35. Zhou Y, He CH, Yang DS, et al. Galectin-3 interacts with the CHI3L1 axis and contributes to Hermansky-Pudlak syndrome lung disease. J Immunol 2018;200 $2140-2153$.

36. Francescone RA, Scully S, Faibish M, et al. Role of YKL-40 in the angiogenesis, radioresistance, and progression of glioblastoma. J Biol Chem 2011;286: $15332-15343$.

37. Geng B, Pan J, Zhao T, et al. Chitinase 3-like 1-CD44 interaction promotes metastasis and epithelial-to-mesenchymal transition through $\beta$-catenin/Erk/Akt signaling in gastric cancer. J Exp Clin Cancer Res 2018;37:1-20.

38. Low D, Subramaniam R, Lin L, et al. Chitinase 3-like 1 induces survival and proliferation of intestinal epithelial cells during chronic inflammation and colitisassociated cancer by regulating S100A9. Oncotarget 2015;6:36535-36550.

39. Dichev V, Kazakova M, Sarafian V. YKL-40 and neuron-specific enolase in neurodegeneration and neuroinflammation. Rev Neurosci 2020;31:539-553.

40. Yeo IJ, Lee CK, Han SB, Yun J, Hong JT. Roles of chitinase 3-like 1 in the development of cancer, neurodegenerative diseases, and inflammatory diseases. Pharmacol Ther 2019;203:107394.

41. Kim DH, Park HJ, Lim S, et al. Regulation of chitinase-3-like-1 in T cell elicits Th1 and cytotoxic responses to inhibit lung metastasis. Nat Commun 2018;9:503.

42. Deutschmann C, Roggenbuck D, Schierack P. The loss of tolerance to CHI3L1: putative role in inflammatory bowel disease? Clin Immunol 2019;199:12-17.

43. Kjaergaard AD, Johansen JS, Bojesen SE, Nordestgaard BG. Role of inflammatory marker YKL-40 in the diagnosis, prognosis and cause of cardiovascular and liver diseases. Crit Rev Clin Lab Sci 2016;53:396-408.

44. Yeo IJ, Lee CK, Han SB, Yun J, Hong JT. Roles of chitinase 3-like 1 in the development of cancer, neurodegenerative diseases, and inflammatory diseases. Pharmacol Ther 2019;203:107394.

45. Di Rosa M, Malaguarnera L. Chitinase 3 like-1: an emerging molecule involved in diabetes and diabetic complications. Pathobiology 2016;83:228-242.

46. Libreros S, Iragavarapu-Charyulu V. YKL-40/CHI3L1 drives inflammation on the road of tumor progression. J Leukoc Biol 2015;98:931-936.

47. Shao R, Hamel K, Petersen L, et al. YKL-40, a secreted glycoprotein, promotes tumor angiogenesis. Oncogene 2009;28:4456-4468.

48. Ranok A, Wongsantichon J, Robinson RC, Suginta W. Structural and thermodynamic insights into chitooligosaccharide binding to human cartilage chitinase 3-like protein 2 (CHI3L2 or YKL-39). J Biol Chem 2015;290:2617-2629.

49. Prakash M, Bodas M, Prakash D, et al. Diverse pathological implications of YKL-40 answers may lie in "outside-in" signaling. Cell Signal 2013;25:1567-1573.

50. Steck E, Breit S, Breusch SJ, Axt M, Richter W. Enhanced expression of the human chitinase 3-like 2 gene (YKL-39) but not chitinase 3-like 1 gene (YKL-40) in osteoarthritic cartilage. Biochem Biophys Res Commun 2002;299:109-115.

51. Pusztai C, Yusenko MV, Banyai D, Szanto A, Kovacs G. M2 macrophage marker chitinase 3-like 2 (CHI3L2) associates with progression of conventional renal cell carcinoma. Anticancer Res 2019;39:6939-6943.

52. Liu T, Larionova I, Litviakov N, et al. Tumor-associated macrophages in human breast cancer produce new monocyte attracting and pro-angiogenic factor YKL-39 indicative for increased metastasis after neoadjuvant chemotherapy. Oncoimmunology 2018;7:e1436922.

53. Arias EB, Verhage HG, Jaffe RC. Complementary deoxyribonucleic acid cloning and molecular characterization of an estrogen-dependent human oviductal glycoprotein. Biol Reprod 1994;51:685-694.

54. Kzhyshkowska J, Mamidi S, Gratchev A, et al. Novel stabilin-1 interacting chitinaselike protein (SI-CLP) is up-regulated in alternatively activated macrophages and secreted via lysosomal pathway. Blood 2006;107:3221-3228.

55. Gilhus NE, Deuschl G. Neuroinflammation-a common thread in neurological disorders. Nat Rev Neurol 2019;15:429-430.

56. Steinacker P, Verde F, Fang L, et al. Chitotriosidase (CHIT1) is increased in microglia and macrophages in spinal cord of amyotrophic lateral sclerosis and cerebrospinal fluid levels correlate with disease severity and progression. J Neurol Neurosurg Psychiatry 2018;89: 239-247.

57. Mishra PS, Vijayalakshmi K, Nalini A, et al. Etiogenic factors present in the cerebrospinal fluid from amyotrophic lateral sclerosis patients induce predominantly proinflammatory responses in microglia. J Neuroinflammation 2017;14:1-18.

58. Xiao $\mathrm{Q}, \mathrm{Yu} \mathrm{W}$, Tian $\mathrm{Q}$, et al. Chitinasel contributed to a potential protection via microglia polarization and $\mathrm{A} \beta$ oligomer reduction in $\mathrm{D}$-galactose and aluminum-induced rat model with cognitive impairments. Neuroscience 2017;355:61-70.

59. Wang X, Yu W, Fu X, Ke M, Xiao Q, Lü Y. Chitotriosidase enhances TGFß-Smad signaling and uptake of $\beta$-amyloid in N9 microglia. Neurosci Lett 2018;687:99-103.

60. Bonneh-Barkay D, Wang G, Starkey A, Hamilton RL, Wiley CA. In vivo CHI3L1 (YKL-40) expression in astrocytes in acute and chronic neurological diseases. J Neuroinflammation 2010;7:1-8.

Data available from Dryad. Additional e-references (e1-e101) available at: links.lww. com/NXI/A351. 


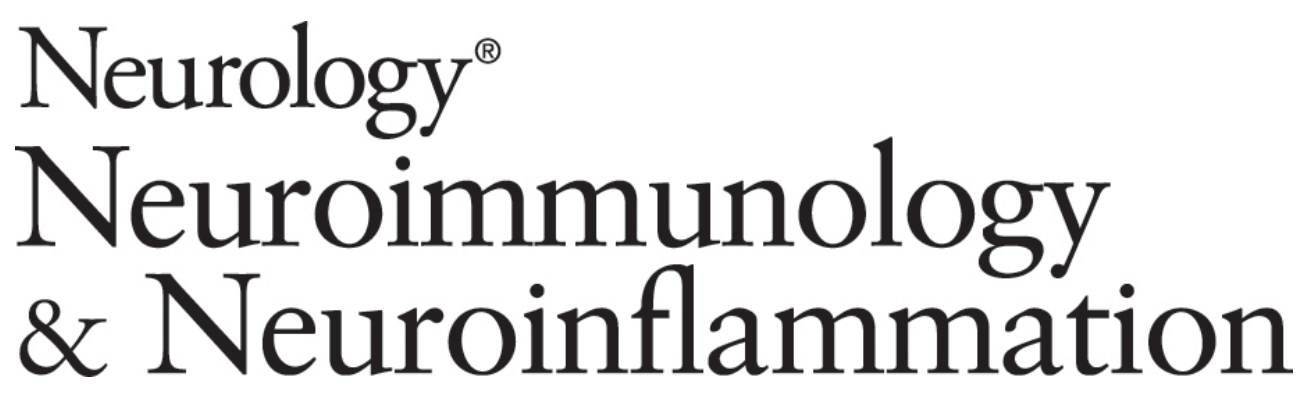

Chitinases and chitinase-like proteins as biomarkers in neurologic disorders Rucsanda Pinteac, Xavier Montalban and Manuel Comabella

Neurol Neuroimmunol Neuroinflamm 2021;8;

DOI 10.1212/NXI.0000000000000921

This information is current as of December 8, 2020

Neurol Neuroimmunol Neuroinflamm is an official journal of the American Academy of Neurology.

Published since April 2014, it is an open-access, online-only, continuous publication journal. Copyright

Copyright $\odot 2020$ The Author(s). Published by Wolters Kluwer Health, Inc. on behalf of the American Academy of Neurology.. All rights reserved. Online ISSN: 2332-7812.

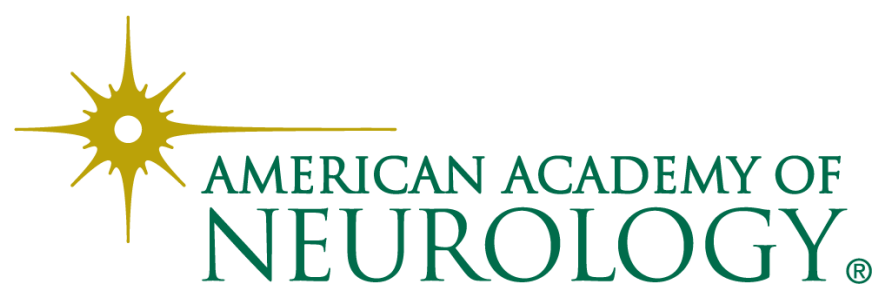




\section{Updated Information \& Services}

References

Citations

Subspecialty Collections

Permissions \& Licensing

Reprints including high resolution figures, can be found at:

http://nn.neurology.org/content/8/1/e921.full.html

This article cites 59 articles, 15 of which you can access for free at: http://nn.neurology.org/content/8/1/e921.full.html\#\#ref-list-1

This article has been cited by 1 HighWire-hosted articles: http://nn.neurology.org/content/8/1/e921.full.html\#\#otherarticles

This article, along with others on similar topics, appears in the following collection(s):

All Immunology

http://nn.neurology.org//cgi/collection/all_immunology

Alzheimer's disease

http://nn.neurology.org//cgi/collection/alzheimers_disease

Amyotrophic lateral sclerosis

http://nn.neurology.org//cgi/collection/amyotrophic_lateral_sclerosis_ Multiple sclerosis

http://nn.neurology.org//cgi/collection/multiple_sclerosis

Information about reproducing this article in parts (figures,tables) or in its entirety can be found online at:

http://nn.neurology.org/misc/about.xhtml\#permissions

Information about ordering reprints can be found online:

http://nn.neurology.org/misc/addir.xhtml\#reprintsus

Neurol Neuroimmunol Neuroinflamm is an official journal of the American Academy of Neurology.

Published since April 2014, it is an open-access, online-only, continuous publication journal. Copyright

Copyright $\odot 2020$ The Author(s). Published by Wolters Kluwer Health, Inc. on behalf of the American

Academy of Neurology.. All rights reserved. Online ISSN: 2332-7812.

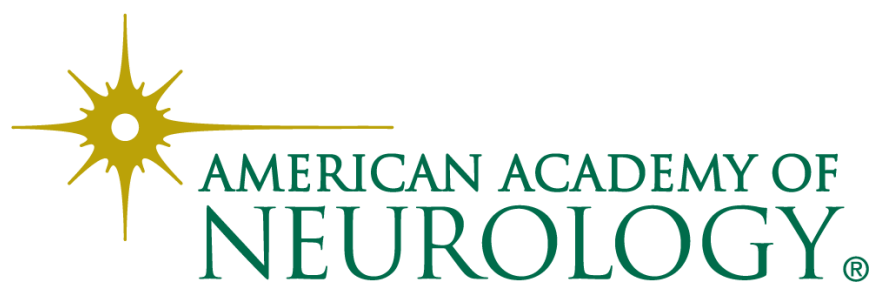

